\title{
Ewolucja zrównoważonej karty wyników
}

https://doi.org/10.33141/po.2005.06.06

\section{Marek Ćwiklicki}

\section{Wstęp}

M etoda Balanced Scorecard (BSC) znana w polskiej literaturze pod nazwą (strategiczna) zrównoważona karta wyników miała swój debiut trzynaście lat temu ${ }^{1}$. $\mathrm{W}$ czasopismach poświęconych naukom o zarządzaniu coraz częściej można znaleźć opracowania prezentujące ramy metodologiczne tej metody oraz zastosowania i adaptacje do krajowych warunków funkcjonowania. Trudno oprzeć się refleksji, że autorzy tych opracowań przedstawiając BSC eksponują odmienne aspekty, co sprawia, że jego istota ulega rozmyciu. Winę za ten fakt ponosi cześciowo proces ewolucji zrównoważonej karty wyników od narzędzia pomiaru efektywności do „systemu zarządzania wspomagającego wdrożenie strategii”").

\section{Geneza metody BSC}

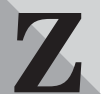

równoważona karta wyników powstała w wyniku jednorocznego projektu „Mierzenie efektywności w organizacjach przyszłości” z 1990 r., zrealizowanego przez zespół pod kierownictwem Davida Nortona, ówczesnego dyrektora Instytutu Nolan Norton. Skład zespołu tworzyli przedstawiciele 12 przedsiębiorstw, w tym: Advanced Micro Devices, American Standard, Apple Computer, Bell South, CIGNA, Conner Peripherals, Cray Research, DuPont, Electronic Data Systems, General Electric, Hewlett Packard i Shell Kanada [Kaplan, Norton 2002, s. 17].

W grudniu tego samego roku, po sześciu spotkaniach, w trakcie których omawiano nowe systemy mierzenia efektywności, przedstawiono raport zalecający wielowymiarową ocenę funkcjonowania przedsiębiorstwa.

Źródłem inspiracji dla D. Nortona oraz R. Kaplana, konsultanta naukowego projektu, była karta wyników korporacji (corporate scorecard) Analog Devices Inc., zaprezentowana przez Arthura Schneidermana, pełniącego w tej firmie funkcję wiceprezesa ds. jakości i wydajności [Kaplan, Norton 2002, s. 17-18; Schneiderman 2004].

Warto w tym miejscu wyjaśnić pochodzenie karty korporacyjnej. Otóż pierwsza karta wyników została opracowana w roku $1987 \mathrm{w}$ wyniku stosowania przez Analog Devices metody hoshin kanri ${ }^{3}$, wykorzystywanej do skoncentrowania uwagi całej organizacji na realizacji kilku celów rocznie [Schneiderman 2004]. Sam Schneiderman dobrze znał tę metodę: pomogły $\mathrm{mu} \mathrm{w}$ tym pobyt $\mathrm{w}$ Japonii oraz kontakty z pracowni-
Przegląd Organizacji, Nr 6 (785), 2005, ss. 26-28 Www.przegladorganizacji.pl Towarzystwo Naukowe Organizacji i Kierownictwa (TNOiK) kami firmy Hewlett-Packard, w której stosowano to podejście. W korespondencji wymienionej w październiku 2004 r. pomiędzy autorem niniejszego artykułu a A. Schneidermanem, na pytanie o „ojcostwo” zrównoważonej karty wyników, były pracownik Analog Devices przyznał, że metoda hoshin była jednym z antenatów zrównoważonej karty wyników. Podobne potwierdzenie znaleźć można w artykule Kaplana i Nortona z 1993 roku [1993, s. 142] $]^{4}$.

Daniel Meade, kierownik Instytutu Efektywności z Monterrey, wskazuje na japońskie hoshin kanri oraz francuskie Tableau de Bord, jako na dwie główne metody, będące „korzeniami” zrównoważonej karty wyników, chociaż, jak sam zaznacza, występują pomiędzy nimi znaczące różnice $\mathrm{w}$ celu i strukturze [Meade]. Związki z Tableau de Bord podkreśla także A. Jaruga w przedmowie do książki Nortona i Kaplana [2002, s. 9]. Metoda BSC różni się od francuskiej metody ujęciem mierników w „ciąg powiązanych logicznie celów i wskaźników, spójnych i wzajemnie uzupełniających się" [Kaplan, Norton 2002, s. 45].

\section{Stadia rozwojowe metody BSC i perspektywy jej rozwoju}

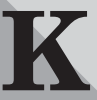

oncepcja BSC opisana na początku lat 90. ub. wieku, odnosząca się przede wszystkim do pomiaru efektywności organizacji, była substratem I generacji zrównoważonych kart wyników. Podstawowym celem ich stosowania był pomiar działalności poprzez dekompozycję strategii na cztery kluczowe perspektywy oraz określenie mierników realizacji ustalonych celów. Podkreślono w ten sposób potrzebę uwzględnienia pozafinansowych aspektów funkcjonowania organizacji. Jednak pierwotne ograniczenie zakresu stosowania tylko do spraw strategicznych spowodowało, że twórcy metody postanowili dokonać modyfikacji jej aspektów metodycznych [Przegląd... 2001, s. 11].

II generacja zrównoważonych kart wyników pojawiła się w połowie lat 90. ub. wieku. Jak zauważają A. Bourguignon, V. Malleret i H. N $\phi$ rreklit [2001, s. 5] w promocji tej koncepcji w literaturze zarządzania aktywny udział brali sami twórcy metody, czego dowodem jest ich wzmożona działalność pisarska [Kaplan, Norton 1996a, 1996b, 1997]. W tym okresie publikowano doniesienia o wdrożeniach zrównoważonej karty wyników przez menedżerów i konsultantów, którzy dostrzegli inne zastosowania tej metody. Podejście to, nazwane przez Morisawę II generacją, odznaczało się dodatkowo: 
- organizacyjnym uczeniem się,

- identyfikacją i rozwiązywaniem problemów operacyjnych,

- informacją zwrotną dla przyszłych planów,

- budowaniem wiedzy organizacyjnej,

- stosowaniem cyklu zarządzania PDCA [Morisawa 2002, s. 4-6].

Dla II generacji zrównoważonych kart wyników kluczowe były kwestie komunikacji wyników konfrontacji celów i działań w organizacji.

W 2001 r. Kaplan i Norton dodali do swojej koncepcji nowe elementy, tworząc ramy III generacji zrównoważonych kart wyników. To podejście można określić mianem „systemu zarządzania wspomagającego wdrożenie strategii” lub „modelem organizacyjnej zmiany”. W 2002 r. D. Norton pisał wprost: „zarządzanie strategia jest zarządzaniem zmianą" [2002, s. 1]. Twórcy metody wzbogacili ją o następujące elementy:

- zarządzanie zmianą,

- mapę strategii,

- strumień i wzorzec strategii,

- komunikację strategiczna,

- integrację budżetu z planem personalnym,

- zmianę klimatu organizacyjnego [Morisawa 2002, s. 4-6].

Za najważniejszy z nowych atrybutów III generacji zrównoważonych kart wyników należy uznać mapę strategii, w której odwzorowuje sie „(...) proces transformacji aktywów niematerialnych w materialne efekty finansowe" [Kaplan, Norton 2001, s. 77]. Przypomina ona $\mathrm{w}$ swej istocie, dobrze znany $\mathrm{w}$ systemie kompleksowego zarządzania jakością, diagram przyczynowo-skutkowy, w którym - w tym konkretnym przypadku - dane wejściowe stanowią zadania strategiczne.
Przedstawiona ewolucja zrównoważonej karty wyników skłania do formułowania pytań o jej przyszłość. Najwyraźniej jej twórcy również o tym myślą. Otóż na stronach internetowych przedsiębiorstwa IDS Scheer znajduje się informacja o porozumieniu podpisanym przez tę firmę z Balanced Scorecard Collaborative, w wyniku którego powstało Balanced Scorecard Collaborative CEE (Central and Eastern Europe). Jak informuje IDS Scheer: „Głównym celem współpracy obu firm jest połączenie wiedzy IDS Scheer z zakresu procesów biznesowych z doświadczeniem w dziedzinie doradztwa strategicznego BSCol" [IDS Scheer Polska 2005]. Już pojawiają się zapowiedzi, że: „W najbliższym czasie nastapi integracja narzędzi ARIS i BSCol oraz metodyk obu firm dla przedsięwzięć projektowania Strategicznej Karty Wyników i zarządzania procesami biznesowymi. W najbliższym czasie Strategiczna Karta Wyników i zarządzanie procesami biznesowymi stworzą jedno, współdziałające narzędziowo i metodologicznie narzędzie" [tamże].

Z krótkiej charakterystyki „produktu”, mającego powstać na skutek prac w BSCol CEE, wynika, że menedżerowie mogą się spodziewać nowego oprogramowania wspomagającego integrację zarządzania procesami biznesowymi ze zrównoważoną kartą wyników.

Nie jest to pierwszy przypadek współpracy BSCol z przedsiębiorstwem oferującym informatyczne rozwiązania z zakresu zarządzania. Przypomnieć w tym miejscu należy o programie certyfikującym BSCol, w wyniku którego testuje się kompatybilność oprogramowania z metodyką zrównoważonej karty wyników. Na przykład w 2000 r. taki certyfikat przyznano firmie SAP AG za uzupełnienie sztandarowego produktu tej firmy mySAP o moduł zgodny z BSC o nazwie SAP Strategic Enterprise Management [Balanced... 2000].

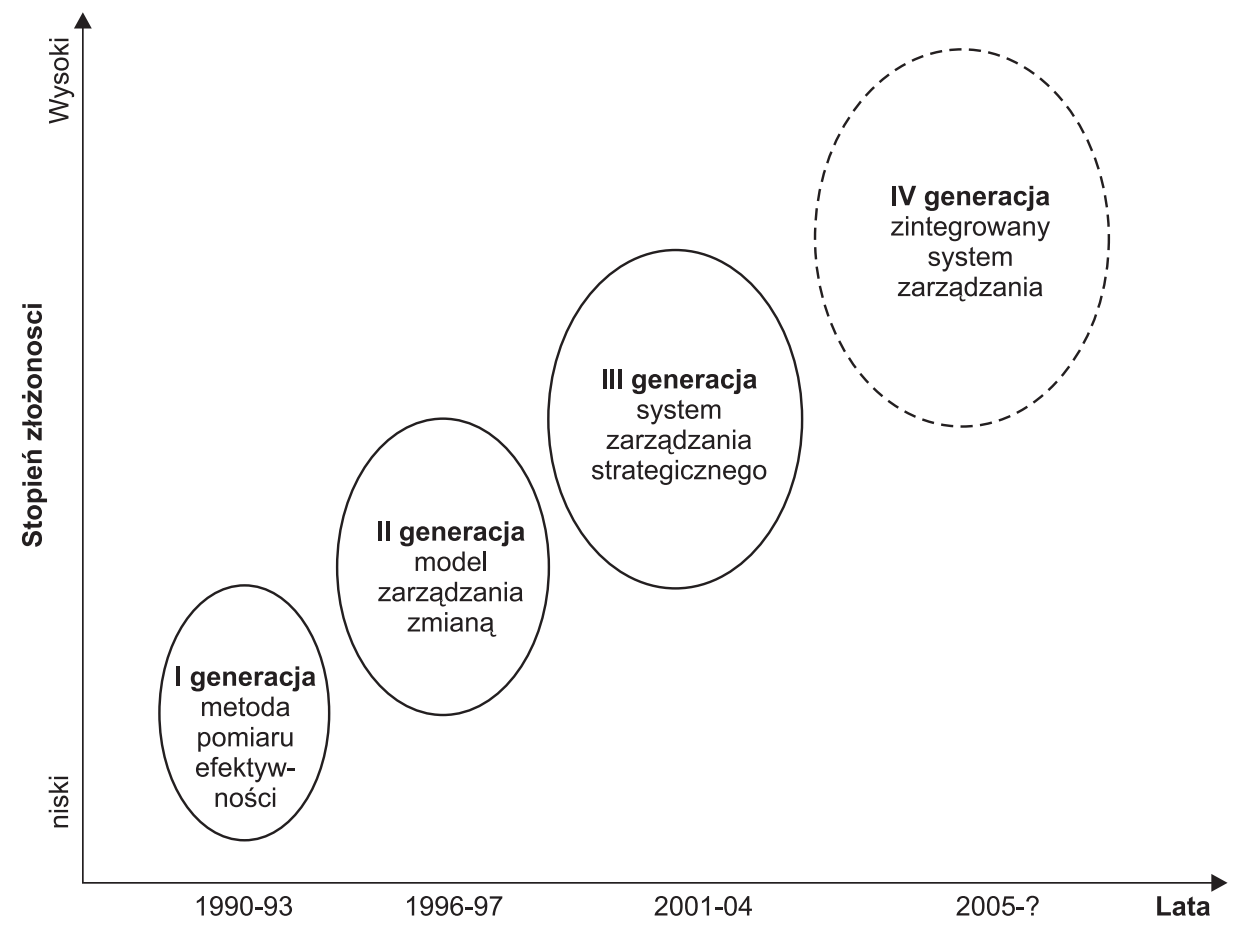

Rys. Ewolucja metody zrównoważonej karty wyników

Źródło: opracowanie własne. 
Jednak współpraca z firmą IDS Scheer może okazać się przełomowa dla dalszego rozwoju metody. Wynika to z rozszerzenia współpracy między obydwiema firmami o kwestie metodyczne, dotyczące procesów biznesowych.

Dotychczasowa działalność Scheera i duetu Kaplan-Norton wydaje się potwierdzać powyższe przypuszczenia. Można pokusić się o stwierdzenie, że ich współpraca jest ułatwiona, ze względu na fakt ujęcia perspektywy procesów wewnętrznych w modelu zrównoważonej karty wyników. Jak zauważają Z. Martyniak i B. Moszoro [2001, s. 19], takie ujęcie perspektywy nie jest niczym nowym, a jej ramy metodologiczne Kaplan i Norton prawdopodobnie zaczerpnęli z łańcucha wartości Portera. R. Kaplan i D. Norton zaznaczaja, że zrównoważona karta wyników powstała niezależnie od Porterowskiego opracowania, chociaż dostrzegają, że obydwie koncepcje mają „ten sam pogląd na temat strategii" [Kaplan, Norton 2001, s. 84]. Różnica pomiędzy BSC a łańcuchem wartości Portera znajduje się w sposobie maksymalizacji wartości [Martyniak, Moszoro 2001, s. 19].

Zintegrowane podejście, będące mariażem dwóch powyżej wymienionych metod, rozpoczyna zdaniem autora IV generację zrównoważonych kart wyników (zob. rys.). Ich głównym wyróżnikiem jest podejście procesowe. Mocną stroną metody ARIS jest komputerowe wspomaganie analizy procesów biznesowych za pomoca oprogramowania ARIS Toolset. Oznacza to, że cecha charakterystyczna tej generacji BSC jest wyższy stopień zastosowania technik informatycznych. Korzystanie z rozwiązań nowoczesnej technologii jest spowodowane wzrastającym stopniem złożoności metody, tj. uwzględnianiem coraz większej liczby punktów widzenia na zarządzanie przedsiębiorstwem. Najbliższe lata pokażą, czy ta przyszłościowa generacja istotnie spełni oczekiwania jej twórców.

\section{Zakończenie}

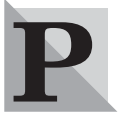

rzedstawiony rozwój BSC jest przykładem występowania powszechnego zjawiska, jakim jest ewolucja metod, często nie dostrzeganego zarówno przez praktyków, jak i teoretyków. Stąd też wynikają niejasności podczas prezentacji metod, ponieważ przedmiotem badań są różne stadia metody. Prowadzi to do sytuacji, w których tzw. studia przypadków zawierają fragmenty szerszej koncepcji z bardziej rozwiniętych form metody.

Ponadto metamorfoza metody BSC potwierdza także główną tendencję w ewolucji metod, tj. przechodzenie od metod heurystycznych, elastycznych, do metod klasycznych, „programów dających się stosować automatycznie" [Martyniak 1987, s. 126-127]. Dowodem na to jest zastosowanie oprogramowania komputerowego. Ostatnia z zaprezentowanych generacji odznacza się systematycznym ujęciem zarządzania, które można realizować zgodnie z opracowanym w III generacji metody tokiem postępowania.

dr Marek Ćwiklicki

Katedra Metod Organizacji i Zarządzania Akademia Ekonomiczna w Krakowie

\section{PRZYPISY}

1) Wyczerpujacy opis metody został przedstawiony w pracach R. Kaplana i D. Nortona [2001, 2002].

2) Takie określenie zostało użyte w programie seminarium pt. „,[R]Ewolucja Balanced Scorecard: Budowanie organizacji skupionej na strategii” prowadzonym przez R. Kaplana 9 lutego 2005 r. w Warszawie.

3) O metodzie hoshin kanri czytelnik może przeczytać m.in. w pracy Z. Martyniaka [1998].

4) Podobieństwa między metodą hoshin kanri a BSC są widoczne zwłaszcza przy uwzględnieniu III generacji metody. Dotyczy to następujących płaszczyzn: zasad, perspektyw postrzegania organizacji, charakteru identyfikowanych celów, rodzajów mierników oceny działalności, toku postępowania i liczby elementów podlegających kontroli [Ćwiklicki 2005].

\section{BIBLIOGRAFIA}

[1] Balanced Scorecard Collaborative Awards Certification to SAP ${ }^{\mathrm{TM}}$ Strategic Enterprise Management ${ }^{\mathrm{TM}}$, http://www. bscol.com/bscol/press/index.cfm?id=CD808362-BC09-11D4A8C400508BDC96C1

[2] BOURGUIGNON A., MALLERET V., NØRREKLIT H. [2001], Balanced Scorecard versus French Tableau de Bord: Beyond Dispute, a Cultural and Ideological Perspective, „Les Cahiers de Recherche", nr 724.

[3] ĆWIKLICKI M. [2005], Hoshin kanri a zrównoważona karta wyników, „Zeszyty Naukowe Akademii Ekonomicznej w Krakowie" (w druku).

[4] IDS Scheer Polska [2005], „IDS Scheer rozpoczyna współpracę z Davidem P. Nortonem i Robertem S. Kaplanem", dostęp: http://www.ids-scheer.pl/index2.php?strona=news/news71.php, dostęp: 10.01.2005.

[5] KAPLAN R.S., NORTON D.P [2001], Strategiczna karta wyników. Praktyka, Wyd. CIM, Warszawa.

[6] KAPLAN R.S., NORTON D.P [2002], Strategiczna karta wyników. Jak przełożyć strategię na działanie, wyd. 2, Wyd. Nauk. PWN, Warszawa.

[7] KAPLAN R.S., NORTON D.P. [1993], Putting the Balanced Scorecard to Work, „Harvard Business Review”, wrzesień-październik, s. 134-147.

[8] KAPLAN R.S., NORTON D.P. [1996a], The Balanced Scorecard, Harvard Business School Press, Boston.

[9] KAPLAN R.S., NORTON D.P. [1996b], Using the Balanced Scorecard as a Strategic Management System, „Harvard Business Review" 74, 1, s. 75-85.

[10] KAPLAN R.S., NORTON D.P. [1997], Why Does Business Need a Balanced Scorecard?, „Journal of Cost Management" 11,3 , s. 5-10.

[11] MARTYNIAK Z. [1987], Organizatoryka, PWE, Warszawa.

[12] MARTYNIAK Z. [1998], HOSHIN - japońska metoda zarzadzania, „Organizacja i Kierowanie”, nr 4.

[13] MARTYNIAK Z., MOSZORO B. [2001], Podejście procesowe $w$ wybranych koncepcjach zarzadzania, [w:] Zarzadzanie firma - teoria i praktyka. Wybrane zagadnienia. Management - Theory and Practice. Selected Issues, red. W. WASZKIELEWICZ, Wydział Zarządzania Akademii Górniczo-Hutniczej w Krakowie, Kraków, s. 15-24.

[14] MEADE D., The Regulatory Dimension and the Balanced Scorecard, „BetterManagement.com” http://www.bettermanagement.com/Library/Library.aspx?LibraryID $=10557$. [15] MORISAWA T. [2002], Building Performance Measurement Systems with the Balanced Scorecard Approach, „Nomura Research Institute (NRI) Papers", nr 45, kwiecień 1. [16] NORTON D. [2002], Managing Strategy is Managing Change, „Balanced Scorecard Report”, vol. 4, nr 1, styczeńluty.

[17] Przeglad popularnych koncepcji zarzadzania [2004], „Zarządzanie na Świecie”, nr 1, s. 10-17.

[18] Schneiderman A.M. [2004], Analog Devices: 1986-1992. The First Balanced Scorecard, http://www.schneiderman. com/Concepts/The First_Balanced Scorecard/BSC INTRO_AND_CONTENTS.htm 